\title{
Levantamento e análise dos dados da presença feminina discente no curso de Bacharelado em Sistemas de Informação do Instituto Federal Catarinense, campus Camboriú
}

\author{
Ana Elisa Schmidt, Hiryna Philipps de Britto, Mozara Dias Koehler ${ }^{1}$ \\ ${ }^{1}$ Instituto Federal Catarinense- Campus Camboriú- Joaquim Garcia S/N-Camboriú- SC \\ anaelisa@ifc-camboriu.edu.br, hiryna@ifc-camboriu.edu.br, mozara@ifc- \\ camboriu.edu.br
}

\begin{abstract}
This article presents a survey and data analysis about the student female presence in the Information Systems Bachelor course at Instituto Federal Catarinense, campus Camboriú. Comparative data with the male students' presence is presented and further discussed.
\end{abstract}

Resumo. Este artigo apresenta o levantamento e análise dos dados da presença feminina discente no curso de Bacharelado em Sistemas de Informação do IFCCamboriú desde a criação do curso. Apresenta-se comparativos com dados dos discentes do sexo masculino visando evidenciar as diferenças encontradas.

\section{Mulheres na informática}

Segundo Felitti, em 1974 as mulheres representavam 70\% da primeira turma do bacharelado em ciência da computação do Instituto de Matemática e Estatística (IME). Muito antes disso a equipe que programava o ENIAC era formada por mulheres. Mas a partir dos anos 2000 a realidade na área de computação começou a mudar. Um exemplo disso é citado pela influenciadora digital Camila Achutti [Achutti, 2016] que diz ter sido única mulher formada no IME no curso de ciência da computação [Felitti, 2015].

O Google preocupou- se com essa diferença entre número de homens e mulheres em 2014, avaliando que somente 30\% dos funcionários da empresa em todo mundo eram mulheres. Segundo análise do Google, o baixo número de mulheres que se formam em ciência da computação, cerca de $18 \%$, seria um dos motivos para a presença inferior das mulheres no mercado de TI. Nas grandes empresas de tecnologia a porcentagem de mulheres empregadas nas mesmas é bastante parecida com as apresentadas pelo Google [Cruz, 2014].

Para alguns autores, o estímulo e a interação com objetos tecnológicos nos homens vem desde a infância, enquanto nas mulheres isso não acontece. As escolas mistas deveriam reduzir os estereótipos, mas acontece o inverso. As inovações tecnológicas seduzem muito mais os homens, fato este que inibe o avanço das mulheres no mercado de trabalho tecnológico além das diferenças salariais [Rapkiewicz, 1998].

Visando colaborar na discussão sobre o esclarecimento e incentivo à participação feminina dentro dos cursos superiores da área de ciência da computação, este artigo apresenta um levantamento e análise dos dados da presença feminina discente no curso de Bacharelado em Sistemas de Informação do IFC-CAM desde sua criação em 2010 até os dias de hoje. 


\section{2. $O$ ingresso feminino discente no curso de Bacharelado em Sistemas de Informação do IFC- CAM}

$\mathrm{O}$ curso de Bacharelado em Sistemas de Informação do Instituto Federal Catarinense Campus Camboriú - BSI/IFC-CAM - teve seu início no ano de 2010. O ingresso neste curso é anual, tendo atualmente como forma de ingresso a seleção pelo SISU e, posteriormente, caso haja vagas remanescentes, a análise curricular. As disciplinas são ofertadas semestralmente no período matutino.

O curso tem seu foco voltado para a formação do profissional que irá desenvolver ou gerenciar sistemas aplicativos e de gestão de informações. Entre os objetivos do curso estão: preparar profissionais para identificar as necessidades das organizações, criar e gerir soluções tecnológicas e desenvolver sistemas informatizados para organizar os fluxos de informação das empresas [IFC-CAM, 2016].

A seguir será apresentado o resultado do levantamento da presença feminina no curso BSI/IFC-CAM, através dos gráficos e suas respectivas discussões.

A figura 1 mostra o gráfico comparativo entre o número de homens e mulheres ingressantes no curso desde o primeiro ano, em 2010. O percentual médio de ingresso masculino no período em questão é de $80,3 \%$, enquanto que o feminino é de $19,7 \%$. Observa-se assim a superioridade no ingresso do público masculino, desde a criação do curso, o que nos remete a pergunta para discussão futura: quais os fatores que influenciam a predominância do ingresso masculino no curso do BSI/IFC-CAM.

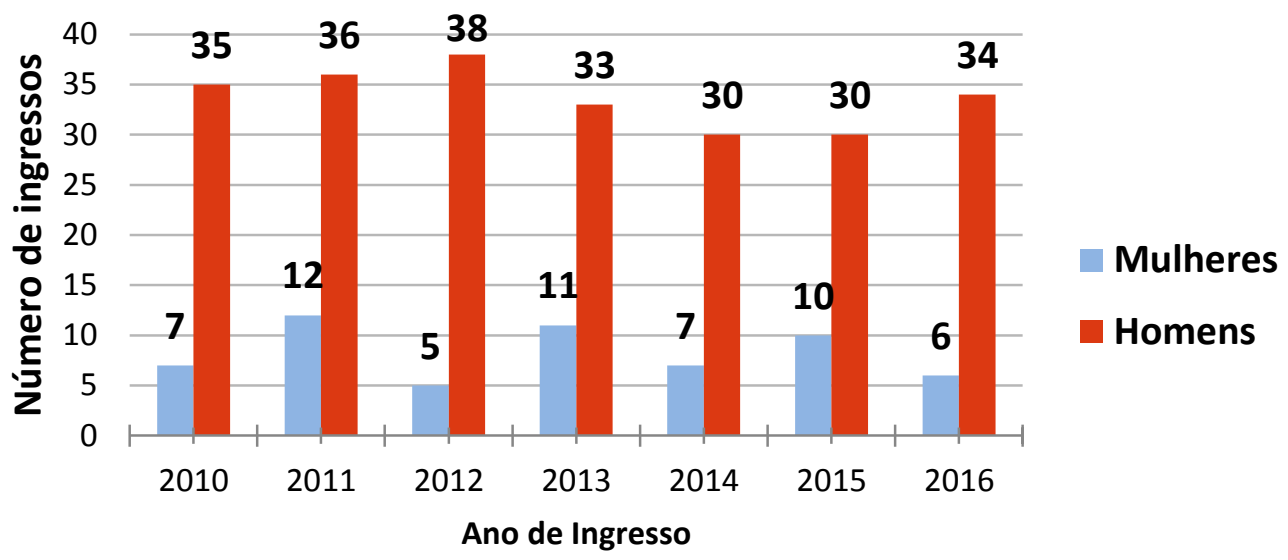

Figura 1- Relação de mulheres e homens ingressantes

A figura 2 apresenta a trajetória do ingresso das mulheres no BSI/IFC-CAM desde 2010. Observa-se que no ano de 2011 o curso teve o maior número de mulheres ingressantes, mas no ano seguinte também foi o menor ingresso. A média anual de mulheres ingressantes é de 07 mulheres/ano, o que ressalta o alto índice de ingresso feminino no ano de 2011, com 05 representantes a mais que a média. 


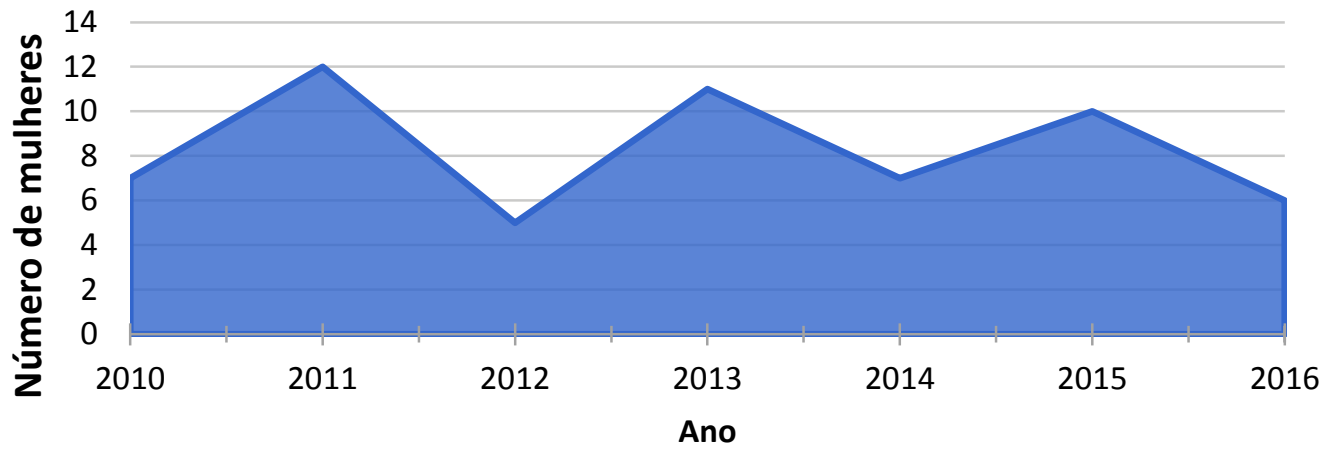

Figura 2- Trajetória do ingresso feminino

A figura 3 demonstra que o número de discentes matriculados a cada ano do sexo masculino cresceu de forma linear enquanto o dos matriculados do sexo feminino obteve um crescimento menos acentuado, permanecendo praticamente estável desde 2014.

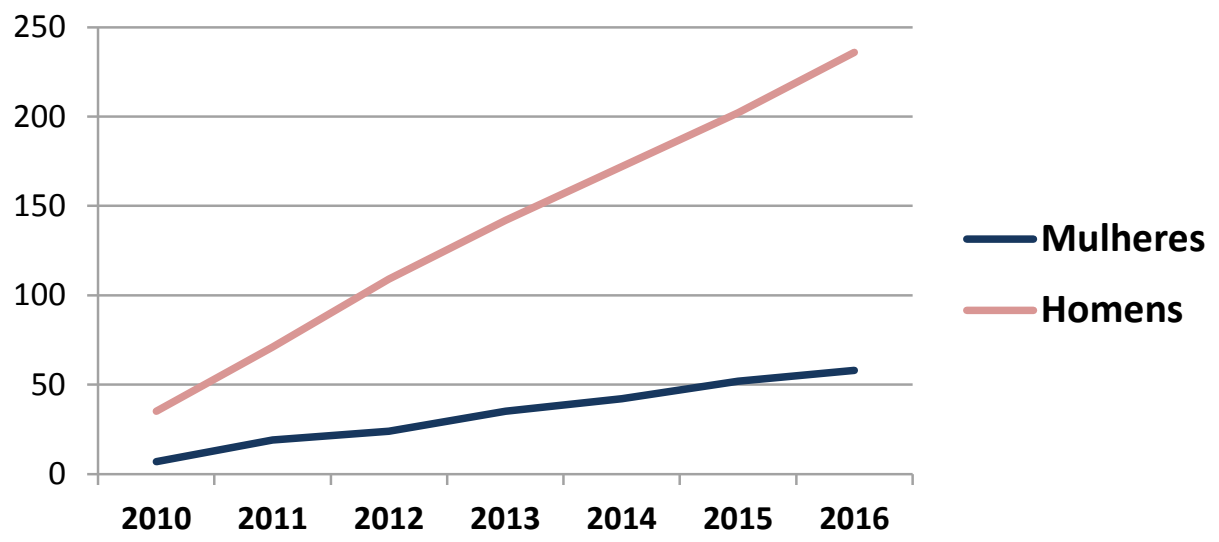

Figura 3 - Número de discentes matriculados por gênero

\section{Formadas $\mathrm{x}$ formados}

A figura 4 apresenta o número de formados por gênero. O gráfico apresenta uma quantidade quase seis vezes maior de formados do sexo masculino em relação aos discentes do sexo feminino.

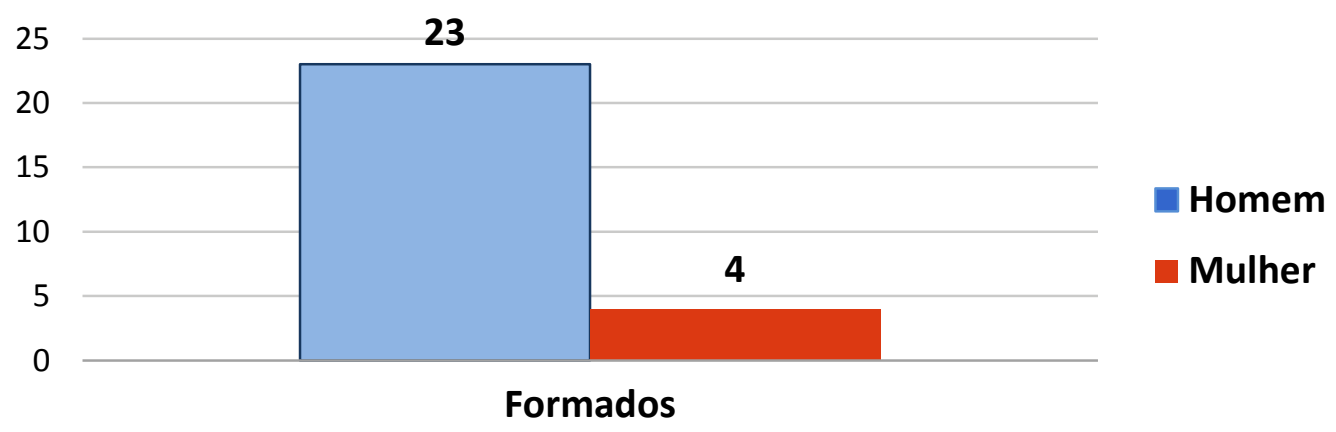

Figura 4 - Comparação entre formados por gênero 
A seguir as figuras 5 e 6 apresentam o percentual de formados com relação ao ingresso por gênero. Estes gráficos demostram que o número de mulheres formadas é somente $2,4 \%$ menor que o número de homens formados.

\section{Mulheres}

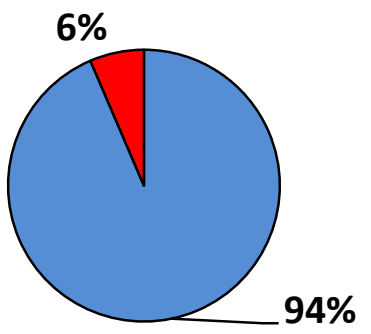

Ingressantes

$\square$ Formadas

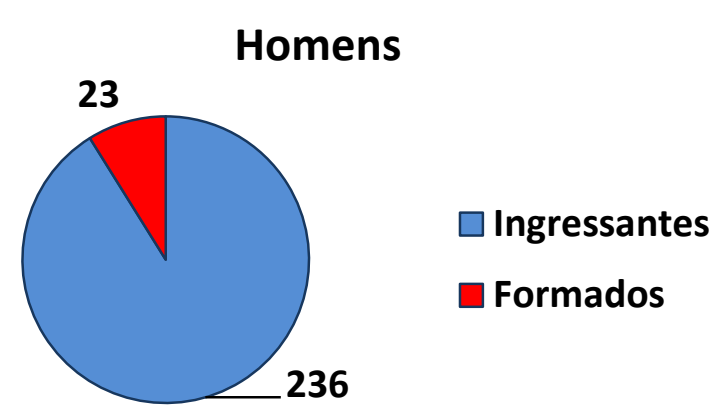

Figuras 5 e 6 - Porcentagem de mulheres formadas e porcentagem de homens formados

\section{Considerações finais}

Analisando todos os gráficos pode- se observar o pequeno ingresso feminino em relação ao masculino, mas a relação ingressantes/formados é equivalente proporcionalmente entre os gêneros.

Esta constatação específica aos anos analisados e ao curso do BSI/IFC-CAM, nos leva a proposição de um novo trabalho onde possa-se aprofundar as pesquisas para verificar quais os fatores que leva a um baixo ingresso feminino, já que dentre a amostra analisada, podemos evidenciar que as mulheres não têm dificuldades maiores que os homens ao fazer o curso do BSI/IFC-CAM pois a porcentagem das formadas em relação ao ingresso é a mesma que os homens.

\section{Referências}

Achutti, C. (2016) "Mulheres na computação", https://mulheresnacomputacao.com/, Maio.

Cruz, L. (2014) "Mulheres buscam mais espaço e diversidade no mercado de tecnologia", http://link.estadao.com.br/noticias/geral,mulheres-buscam-mais-espaco-e-diversidadeno-mercado-de-tecnologia,10000030331, Maio.

Felitti, G. (2015) “Por que há menos mulheres no setor de tecnologia?", http://epocanegocios.globo.com/Informacao/Dilemas/noticia/2015/08/por-que-hamenos-mulheres-no-setor-de-tecnologia.html, Maio.

IFC- CAM, Instituto Federal Catarinense- Campus Camboriú (2015) "Bacharelado em Sistemas de Informação", http://www.camboriu.ifc.edu.br/cursossuperiores/bacharelado-em-sistemas-de-informacao/, Maio.

Rapkiewicz, C. E. (1998). Informática: domínio masculino? http://periodicos.sbu.unicamp.br/ojs/index.php/cadpagu/article/view/4172931, páginas 169-200. Cadernos Pagu, Maio. 